\title{
SERNAC FINANCIERO: NUEVOS DEBERES DE INFORMACIÓN Y RESPONSABILIDAD CIVIL*
}

\section{IGNACIO ROSTIÓN**}

RESUMEN: La Ley $\mathrm{N}^{\circ}$ 20.555, que lleva el nombre ciudadano de "Ley del SERNAC Financiero", alude a un tipo de consumidor en particular -el "consumidor financiero"- quien suele encontrarse en una posición negociadora poco favorable en razón de las asimetrías del mercado financiero. Dado que la confianza es crucial en estos actos de consumo, esta legislación ha puesto el énfasis en un nuevo estatuto de deberes de información, cuyo incumplimiento por parte de las entidades financieras faculta al consumidor financiero para solicitar una indemnización de perjuicios, además de la eventual nulidad del acto, cuando haya sido "inducido a error". El remedio de la responsabilidad va en interés directo del consumidor (a diferencia de las multas que van a beneficio fiscal), de modo que será muy importante para sus intereses cómo nuestra jurisprudencia interpretará los casos en que fue "inducido a error" al negociar en el mercado financiero.

PALABRAS CLAVE: Consumidor financiero - Buena fe contractual Deber de informar - Confianza - Hecho ilícito infraccional.

\section{FINANCIAL SERNAC: NEW DUTIES OF INFORMATION AND CIVIL LIABILITY}

ABSTRACT: The law $\mathrm{N}^{\circ} 20.555$, known by the popular name of "Law of financial SERNAC" makes reference to a sort of particular consumer -the "financial consumer"- which finds itself in a less favorable negotiating position owing to the asymmetries in the financial market. Since trust is crucial in these consumption acts, this legislation has emphasized the new information duties statute. In case this statute is not carried out by the financial institutions, the financial consumer is entitled to request

Fecha de recepción: 12 de septiembre de 2013.

Fecha de aceptación: 17 de marzo de 2014.

** Licenciado en Ciencias Jurídicas y Sociales de la Universidad Alberto Hurtado. Ayudante del Departamento de Derecho Civil de la Universidad Alberto Hurtado. Becario investigador en Universidad de Palermo, Argentina. Correo: ign.rostion@gmail.com. Agradezco los comentarios a una versión anterior de este trabajo del profesor Jorge Larroucau. 
compensation for damages, besides a possible cancellation of the act when it has been "led into error". The responsibility solution is in direct interest of the consumer (unlike fines which are in fiscal benefit), so it will be very important for the consumer's interest the way cases "led into error" are interpreted by our jurisprudence when negotiating in the financial market.

KEY WORDS: Financial Consumer - Contractual Good Faith - Duty to Inform - Trust - Illicit Infringement.

Sumario: 1. Los motivos de la Ley $N^{\circ} 20.555$ y el suicidio moral de no comprender la información financiera; 1.1) Los deberes de información en el contrato de consumo. 1.2) El valor de la confianza en el consumo financiero: El caso del "consumidor medio"; 2. La construcción del deber de información en el consumo de productos financieros según la Ley $N^{\circ} 20.555$; 2.1) La responsabilidad civil por "inducir a error"; 2.2) Las sanciones de la Ley $N^{\circ}$ 20.555: Nulidad, multas y responsabilidad civil.

\section{1) LOS MOTIVOS DE LA LEY N $\mathrm{N}^{\circ} 20.555$ Y EL SUICIDIO MORAL DE NO COMPRENDER LA INFORMACIÓN FINANCIERA}

Es difícil imaginar que el año 1997 la asamblea legislativa chilena hubiera podido predecir todos los supuestos de hecho que en la actualidad afectan a los ciudadanos en su calidad de consumidores. Lo que hizo la Ley sobre Protección a los Derechos de los Consumidores (en adelante LPC) fue preocuparse de que los consumidores tuvieran un conjunto de derechos y deberes a efectos de resguardar sus intereses al adquirir bienes y servicios. Con todo, esta concientización en torno a los derechos de los consumidores se ha estrellado muchas veces con la dura realidad de un consumidor que no consigue hacer valer sus derechos en la práctica, por diversos motivos. Uno de ellos es la falta de información; y otro, la imposibilidad de comprender la información que recibe. Es en este sentido que hoy cobra vigencia lo dicho hace más de un siglo por Rudolf von Ihering, en La lucha por el derecho:

"Tenemos, pues, el deber de defender nuestro derecho, porque nuestra existencia moral es directa y esencialmente atacada en su conservación; desistir completamente de la defensa, cosa hoy no muy en práctica, pero que pudiera llegar a ser puesta en uso, equivale a un suicidio moral" 1 .

Von Ihering, Rudolf (1872), La lucha por el derecho, traducción de Adolfo González Posada, Editorial Heliasta S.R.L, p. 25. 
Los últimos casos de escándalos financieros (La Polar, Cencosud) han coincidido con una reforma al estatuto de los consumidores, insistiendo en el tema del acceso a la información. En el caso del mercado financiero, que es al segmento al que apunta este artículo, la Ley $\mathrm{N}^{\circ} 20.555$ (Ley del SERNAC Financiero, en adelante LSF) que establece nuevos deberes de información en favor de los consumidores de productos financieros, con el objetivo de mitigar las asimetrías de información entre los proveedores y los consumidores. Esta es una meta central de la LSF, como requisito para un desarrollo económico estable al que aspiran las naciones ${ }^{2}$. En efecto, la historia legislativa de la Ley $\mathrm{N}^{\circ} 20.555$ (en adelante HLSF) revela el énfasis en "la existencia de estas asimetrías en el mercado de servicios financieros para particulares, donde las atribuciones actuales del Servicio Nacional del Consumidor no han sido suficientes para resolverlas"3. Allí se destacan las cifras del año 2009, por ejemplo, cuando hubo más de 328 mil consultas y 170 mil reclamos al Servicio Nacional del Consumidor (en adelante SERNAC), en donde más de la mitad de los reclamos de los ciudadanos decían relación con los servicios financieros y de telecomunicaciones.

En este sentido, a través de la LSF y, puntualmente, con los nuevos deberes de información que ella introduce, se buscan reforzar las facultades del SERNAC para "exigir que los proveedores de bienes y los prestadores de servicios entreguen información oportuna y eficaz, para que el consumidor conozca de manera cabal el costo del bien o servicio que recibe y el costo de poner término a una relación de consumo" ${ }^{4}$. Ahora bien, ¿cuáles fueron los factores tomados en cuenta para proteger a los consumidores con la LSF? La respuesta es triple: (a) Mejorar la información a la que pueden acceder los consumidores para la toma de sus decisiones de consumo en asuntos financieros; (b) la creación de una unidad financiera especializada dentro del mismo SERNAC; y (c) otorgar a un ministro de fe las facultades necesarias para certificar los hechos relativos al cumplimiento de la normativa contenida en la LPC. Este artículo se concentra en el impacto del primero de estos factores.

En este sentido, cuando nos ponemos en los zapatos de un consumidor financiero debemos considerar que, para que él pueda disfrutar de un bien o servicio en estos mercados, es preciso dar cuenta de un círculo complejo de actuaciones que lo rodean. Es decir, será necesario tomar en cuenta de que esos mercados están sumidos en su mayoría de "episodios de producción/consumo articulados que probablemente abarcarán marcos

\footnotetext{
2 Ariztía, Tomás, Melero, José y Montero, María (2013), "Un nuevo consumidor chileno: De los derechos a las responsabilidades", en Chile 2009. Percepciones y actitudes sociales, Universidad Diego Portales, pp. 103 ss.

$3 \quad$ Historia de la Ley $\mathrm{N}^{\circ} 20.555,5$ noviembre 2011, p. 6.

$4 \quad$ Historia de la Ley $\mathrm{N}^{\circ} 20.555$, p. 8.
} 
espacio-temporales muy distintos, así como contextos sociales y culturales diversos, donde esos episodios se organizarán en torno a relaciones sociales de producción, distribución y consumo particular" 5 . En otras palabras, estos llamados "episodios de producción/consumo" es lo que, a decir de la Comisión de Economía, Fomento y Desarrollo de la Cámara de Diputados cuando se discutió la LSF, debería llevar a que las empresas financieras comprendiesen que si sus clientes están bien informados y cuentan con la posibilidad real de comprender la información financiera, lo que mejora es la libre competencia y la confianza comercial entre productores y consumidores ${ }^{6}$. Como dijo, entonces, Claudio Ortiz, gerente general del retail financiero:

"Poco se saca con solicitar a los emisores de crédito más información y más regulaciones si lo que hoy en día existe son consumidores que no son capaces de comprender"7.

Buena parte de la discusión de la LSF apuntó hacia un fortalecimiento de la entrega de información comprensible a que acceden los consumidores. Lo anterior es relevante si tenemos a la vista que el "consumidor financiero" constituye una especie de consumidor ("la persona natural o jurídica que en calidad de destinatario final celebre un contrato de servicios crediticios, de seguro y en general, de cualquier producto financiero, ya sea con un banco, con una institución financiera, una sociedad de apoyo a su giro, un establecimiento comercial, una compañía de seguro, una caja de compensación, una cooperativa de ahorro y crédito, o, en general, con cualquier persona natural o jurídica proveedora de dichos servicios o producto" $)^{8}$, que suele estar algo más desamparado que el consumidor

5 Narotzky, Susana (2007), "El lado oculto del consumo", en Cuadernos de antropología social, $\mathrm{N}^{\circ} 26$, p. 25.

$6 \quad$ Historia de la Ley $N^{\circ} 20.555$, pp. 26-28. El Ministro de Economía, Fomento y Turismo, Juan Andrés Fontaine, al intervenir en la discusión parlamentaria, resaltó lo complejo que se ha vuelto el mercado financiero producto de la constante asimetría de información. Los datos de enero y mayo del ańo 2010 eran elocuentes: "13.636 reclamos en contra del mercado financiero; el $61 \%$ de los reclamos se concentra en las tarjetas de crédito del retail y el $33 \%$ en los bancos [...] el 40\% de los reclamos se refiere a cobros indebidos; $14 \%$ a incumplimiento en las condiciones contratadas; $14 \%$ se queja de la mala calidad de los servicios (dificultades para cerrar las cuentas bancarias) y otros: falta de información oportuna en las condiciones relevantes del servicio, cobranzas extrajudiciales abusivas [...] el 23\% de los reclamos se refiere a las mala calidad del servicio; $16 \%$ al incumplimiento de las condiciones contratadas; $13 \%$ respecto a cargos no consentidos por el consumidor; $12 \%$ por facturación excesiva o no justificada y $7 \%$ a falta de información veraz y oportuna. Transporte: el $76 \%$ de los reclamos se refiere a obligaciones del proveedor y el $22 \%$ a derechos del consumidor (falta de información veraz y oportuna, cargos no consentidos por el consumo)".

Historia de la Ley $\mathrm{N}^{\circ} 20.555$, p. 32.

San Martín, Lilian (2013), "Artículo 3 inciso $2^{\circ}$ ", en: Protección de los derechos de los consumidores, comentario a la ley de protección de los derechos de los consumidores, Francisca Barrientos coordinadora, Thomson Reuters, Santiago de Chile, p. 143. 
promedio en términos de acceso y uso adecuado de la información relevante para su toma de decisiones ${ }^{9}$.

\section{1) LOS DEBERES DE INFORMACIÓN EN EL CONTRATO DE CONSUMO}

El contrato cumple un rol muy importante para la circulación de la riqueza, es por medio del contrato que "la titularidad de los bienes se radica en quienes les asignan mayor valor y se promueve el desplazamiento de los recursos hacia usos más eficientes" ${ }^{10}$. En el caso del mercado financiero y de seguros, en particular, su fase de negociación previa (tratativas preliminares) puede resultar compleja, ya que para elegir un cierto producto (como un crédito de consumo o un mutuo hipotecario) es preciso invertir tiempo e incurrir en gastos para conseguir toda la información que se necesita a efectos de obtener el contrato definitivo. ¿Quién va a soportar estos gastos en el caso de una negociación frustrada? La respuesta a una pregunta como esta, en principio, debería responderse teniendo en vista el "principio de autorresponsabilidad"11. Ahora bien, en el caso de los consumidores existe una desigualdad entre las partes, la cual "no se debe a una debilidad constitutiva de adherente, sino que se explica por la circunstancial posición en que se encuentra en el contrato"12. Esta desigualdad se encuentra en la base de la justificación de los deberes de información que tienen los oferentes de productos y servicios financieros.

La contratación masiva no deja de tratar al contrato desde la perspectiva de la libertad (en donde cada uno de los contratantes debe asumir el riesgo en el caso de rupturas las tratativas preliminares, por ejemplo) e insiste en que el contrato es "un instrumento destinado a incentivar y

9 En este sentido es útil revisar los estudios del SERNAC Financiero sobre los créditos hipotecarios y las tasas de interés de los créditos: "Boletín de Crédito Hipotecario (Banca, cooperativa de ahorro y Crédito, Agentes Administradores y Caja de Compensación)”, noviembre 2012, p. 23; "Boletín $N^{\circ}$ 01/2013 Tarjetas de Crédito: Avances en efectivo y compra en cuotas con tarjetas de crédito", febrero 2013, p. 25. "Efectos de la nueva regulación en los seguros de créditos hipotecarios. Análisis en base a la disminución de los costos debido a la ley $N^{\circ}$ 20.552”. Ministerio de Económica, Fomento y Turismo. División de Estudios, septiembre 2012, p. 6. Información disponible en: www.sernacfinanciero.cl [fecha de visita: 15 junio 2013].

10 TApia, Mauricio y Valdivia, José Miguel (2002), Contrato por adhesión Ley $N^{\circ} 19496$, Editorial Jurídica de Chile, p. 17.

11 De la Maza, Ińigo (2010 a), "Tipicidad y atipicidad de los deberes precontractuales de información”, en Revista de Derecho, XXXIV, Pontificia Universidad Católica de Valparaíso, p. 79. Véase, además, De la MazA, Iñigo (2005), "El silencio de los inocentes: Hacia una categorización del deber de informar en cede precontractual", en Estudios de derecho civil, Editorial LexisNexis, pp. 128-177; De la MAZA, Ińigo (2010 b), "El suministro de información como técnica de protección de los consumidores: Los deberes precontractuales de información”, en Revista de Derecho Universidad Católica del Norte, año 17, N² 2, pp. 21 52. "Cada partes soporta el costo de su ignorancia”, p. 43.

Tapia y Valdivia (2002) p. 40. 
fomentar cooperación entre los individuos, permitiendo a las partes negociadoras obtener beneficios a través de la coordinación de sus expectativas mutuas"13. Pero, en este contexto, se vuelve preponderante la idea de que el contrato es una forma de construir confianza ${ }^{14}$ y que, por ello, cobra sentido la "imposición de deberes de conducta en las partes negociadoras y la obligación de negociar de buena fe para actuar en forma leal y honesta"15. En este sentido, como apunta la profesora Lilian San Martín, comentando el caso Jiménez con Armijo, en un fallo de la Corte Suprema: "el fundamento último de la responsabilidad precontractual es la violación del deber de negociar de buena fe, el cual no constituye una obligación precisa, sino un deber genérico de conducta" 16 .

Como se verá en este artículo, los deberes de información que impone la LSF se orientan a fortalecer la posición negociadora del consumidor de productos financieros, a efectos de que el contrato que celebra constituya una expresión de su libertad y de la confianza que existe entre él y quien le provee de un bien o servicio financiero. Cuando se defraudan estos deberes -lo cual implicará una conducta que infringe la buena fe contractual-, la LSF le reconoce al consumidor algunas acciones dirigidas a proteger sus intereses.

\section{2) El VALOR DE LA CONFIANZA EN EL CONSUMO FINANCIERO: EL CASO DEL "CONSUMIDOR MEDIO"}

La información es un bien que, en la actualidad, es más preciado que ciertos activos tangibles ${ }^{17}$. Es el dueño de la información quien se aprovecha de ella, por regla general ${ }^{18}$, aunque en ciertos casos se limita el uso de la información para no afectar algunas cuestiones valiosas (como, por ejemplo, el buen funcionamiento de los mercados: Ley $\mathrm{N}^{\circ} 18.045$ sobre el uso de información privilegiada en el Mercado de Valores). En lo que ahora importa, la información es, además de un bien de propiedad de quien tiene esa información, un elemento imprescindible para el equilibrio entre las partes contratantes dentro de un mercado como el

\footnotetext{
13 Celedón, Rosario y Silberman, Patricia (2010), Responsabilidad precontractual por ruptura de negociaciones contractuales, Editorial Jurídica de Chile, Santiago, p. 23.

14 Tapia y Valdivia (2002) p. 27.

15 Celedón y Silberman (2010) p. 24.

16 SAN Martín, Lilian (2013), "Responsabilidad precontractual por ruptura injustificada de negociaciones”, en Revista Chilena de Derecho, Vol. 40 N 1, Pontificia Universidad Católica de Chile, p. 319.

17 NAROTZKY (2007) p. 32.

18 Barros, Enrique (2006), Tratado de responsabilidad extracontractual, Editorial Jurídica de Chile, Santiago, pp. 1020 ss.
} 
financiero" ${ }^{19}$. Si en Roma "el deber de informar tiene como fin colmar la ignorancia justa, probable, tolerable (Ner. D. 41.10.5.1)"20, en el mercado financiero la información es necesaria para la confianza entre los negociantes.

En efecto, "la confianza no es solo un mecanismo psicológico, que se asienta en los estados de consciencia de los individuos, sino que toda comunicación social está transida de una carga muy fuerte de confianza" 21 . Esto ha llevado a que la información sea considerada nada menos que un bien público en el Reglamento sobre Información al Consumidor de Créditos de Consumo ${ }^{22}$ (en adelante RICC), Reglamento sobre Información al Consumidor de Créditos Hipotecarios ${ }^{23}$ (en adelante RICH) y en el Reglamento sobre Información al Consumidor de Tarjetas de Crédito Bancarias y no Bancarias ${ }^{24}$ (en adelante RICTB). En los anteriores reglamentos se observa una enumeración de las condiciones objetivas que deben cumplir los proveedores financieros cuando negocian con los consumidores, teniendo como principal lineamiento el de otorgar "más y mejor" información a los consumidores (financieros).

Por su parte las ciencias económicas han distinguido entre distintos tipos de bienes en las relaciones de consumo, como los bienes de búsqueda (search goods), de experiencia (experience goods) y los bienes de confianza (credence goods). Estos últimos apuntan al grado de confianza que los individuos tienen en el desempeño de las empresas productoras y en su sistema de control. En este sentido, para los consumidores la información "es el antecedente necesario que permite a los agentes económicos evaluar la incertidumbre, el riesgo y el costo-beneficio que cada alternativa presenta respecto de las otras posibles" 25 y lo cierto es que, en el caso del consumidor financiero, su elección se encuentra sujeta a ciertas restric-

19 Salgado, Catalina (2011), El deber precontractual de información. Contornos desde la perspectiva del sistema del "Ius Romanum" por interacción vertical a partir de la "Ignorantia Factie et Iuris" y la compraventa en el derecho romano, Universidad Degli Studi di Roma "Tor Vergata”, p. 111.

20 Salgado (2011) p. 111.

21 Ghersi, Carlos y Weingarten, Celia (2010), Contratos bancarios, aplicación de la ley del consumidor, Editorial Jurídica Nova Tesis, Rosario, p. 70.

22 Decreto 43: "Aprueba Reglamento Sobre Información al Consumidor de Créditos de Consumo", Ministerio de Economía, Fomento y Turismo; Subsecretaría de Economía y Empresas de Menor Tamaño, D.O. 13 julio 2012.

23 Decreto 42: "Aprueba Reglamento Sobre Información al Consumidor de Créditos Hipotecarios", Ministerio de Economía, Fomento y Turismo; Subsecretaría de Economía y Empresas de Menor Tamańo, D.O. 13 julio 2012.

24 Decreto 44: “Aprueba Reglamento sobre Información al Consumidor de Tarjetas de Crédito Bancarias y no Bancarias", Ministerio de Economía, Fomento y Turismo; Subsecretaría de Economía y Empresas de Menor Tamaño, D.O. 13 julio 2012.

25 Weingarten, Celia (2007), Derecho del consumidor, Editorial Universitaria, Buenos Aires, p. 70 . 
ciones, que entraban una decisión razonada de forma óptima debido a lo encriptado que se presenta al consumidor la información de los productos financieros. Como señala Macarena Barros:

"La educación financiera del crédito se relaciona con contextos informales de socialización en donde las conversaciones con familiares, amigos o gente del trabajo, y la información recibida por los medios de comunicación de masas (a través de reportajes y noticias), sirven como guías de la administración financiera" 26 .

El punto aquí es que, en muchos casos, "el aumento de información en nada contribuyen para tomar una decisión de consumo más libre y racional" 27 , pues, como señala el profesor Enrique Barros, es posible que "un exceso de información resulte contraproducente a efectos de la decisión razonable de una persona lega, que tampoco puede dedicar mucho esfuerzo a descifrarla" 28 . La LSF recoge este punto al señalar en algunos casos qué información se debe otorgar al consumidor, pero sin eximir al intérprete de estos deberes -los jueces- de identificar los casos en que la información entregada no podía ser empleada por el consumidor en su toma de decisiones. De lo que aquí se habla, en otras palabras, es del "criterio de conocimiento personal" que sería necesario explorar en el terreno de los consumidores (sobre todo, de los consumidores financieros), ya que el conocimiento personal de un actor social está condicionado, entre otros factores, por su posición en la estructura económica y social ${ }^{29}$.

En este sentido, la Comunidad Europea habla de un "consumidor medio" como aquel que "está normalmente informado y es razonablemente perspicaz, teniendo en cuenta los factores sociales, culturales y lingüísticos" 30 , mientras que la Organización para la Cooperación y el Desarrollo Económico (OCDE) habla de "consumidores desfavorables o vulnerables" como aquellos que "debido a características o circunstancias personales (por ejemplo, edad, capacidad física o mental, educación, ingreso, idioma o ubicación remota) pueden tener dificultades particulares en el acceso a la resolución de disputas y el resarcimiento" ${ }^{31}$. La cuestión,

26 Barros, Macarena (2012), "En torno al uso del crédito en la industria del retail de Santiago", en: Destapando la caja negra / Sociología de los créditos de consumo en Chile, Instituto de Investigación de Ciencias Sociales (ICSO), p. 120.

Weingarten (2007) p. 71.

Barros (2006) p. 1015.

Morales, Thamara (2010), "Mejores prácticas de educación financiera aplicadas a productos de crédito en el mercado chileno", Facultad de Ciencias Físicas y Matemáticas Departamento de Ingeniería Industrial, Universidad de Chile (William Baeza profesor guía), p. 60. DPCD 2005/29/CE: considerando 18.

31 OCED: "Recomendaciones de la OCDE sobre Resolución de Disputas y Resarcimiento a los Consumidores”, p. 8, disponible en: http://www.oecd.org/mexico/40060255.pdf, [fecha de visita: 20 julio 2013]. 
entonces, es dirimir si el consumidor de productos financieros en Chile se asemeja más a un "consumidor medio" o a un "consumidor desfavorable o vulnerable".

La confianza en el mercado no es un concepto de fácil definición, como lo demuestran, por ejemplo, los indicadores financieros The Conference Board y el de la Universidad de Michigan (ICS o MCSI), que informan acerca de la confianza de los consumidores en el desempeńo de ciertos mercados. Tal como dice Carol Rose, la confianza y el derecho están íntimamente relacionados: "el derecho contribuye a crear condiciones para que haya confianza en un sentido más general”32. Más aún:

"El primer paso para cooperar no tiene nada de racional, sino que responde a las emociones. Si ello es así, entonces también la confianza debe depender de las emociones o, en todo caso, de la evaluación que una persona realiza sobre las emociones de otra [...] todo esto lleva a extraer tres conclusiones. Primero, la racionalidad pura se opone a la confianza. Segundo, la gente confía de todas maneras. Tercero, es importante que así sea, porque sin confianza no podría realizar emprendimientos cooperativos" 33 .

Tal como se verá a continuación, el propósito de los deberes de información establecidos por la LSF es el de hacer probable la confianza en la relación entre los consumidores de productos financieros y los proveedores. La lectura de esta ley da a entender que el consumidor financiero se asemeja más a la figura de un "consumidor medio" (que "está normalmente informado y es razonablemente perspicaz" en su toma de decisiones), en lo que marca un punto de partida importante para el juez que tenga que pronunciarse sobre una demanda de daños presentada por el consumidor en razón de (una supuesta) infracción de estos deberes.

\section{2) LA CONSTRUCCIÓN DEL DEBER DE INFORMACIÓN EN EL CONSUMO DE PRODUCTOS FINANCIEROS SEGÚN LA LEY N ${ }^{\circ} \mathbf{2 0 . 5 5 5}$}

La evolución de los deberes de información en sede precontractual en Chile se expresa en diversas doctrinas, como la teoría del abuso del derecho y la de los actos propios ${ }^{34}$, a la luz de la buena fe que informa

32 Rose, Carol (2010), "Confianza y traición", en El derecho de propiedad como clave interdisciplinaria, Primera Edición, Lucas Grosmman editor, Universidad de Palermo, Buenos Aires, p. 133.

33 Rose (2010) p. 136.

34 Venire contra Factum propium. Escritos sobre la fundamentación, alcance y límites de la doctrina de los actos propios (2010), en Cuadernos de Extensión Jurídica, $\mathrm{N}^{\circ} 18$, Universidad de los Andes, Hernán Corral Talciani editor. 
el iter contractual en nuestro ordenamiento jurídico. Así lo expone, entre otros, la jurisprudencia que surge a propósito de los casos de quien oculta información al declarar su estado de salud (no indica que tiene una enfermedad crónica, por ejemplo) con miras a contratar un seguro médico ${ }^{35}$. Ahora bien, como hace notar el profesor Ińigo de la Maza, "resulta incorrecto extrapolar el establecimiento de un deber de información propio de la regulación de relaciones de consumo -u otras semejantes- a aquellas relaciones disciplinadas por el Código Civil'36 y ello porque los deberes legales de información en el consumo tienen una justificación propia: el acceso a aquella es notoriamente asimétrico entre los consumidores y los proveedores ("el principio es que el contratante en la posición más débil tiene derecho a que le suministren información") ${ }^{37}$ procurando de paso el "mantenimiento de la igualdad entre las partes"38. Este problema de accesibilidad es el punto que recogió el año 2004 la LPC, en cuyo art. 32 se dispuso que el proveedor brindara información al consumidor que fuera "comprensible y legible":

"La información básica comercial de los servicios y de los productos de fabricación nacional o de procedencia extranjera, asi como su identificación, instructivos de uso y garantías, y la difusión que de ellos se haga, deberán efectuarse en idioma castellano, en términos comprensibles y legibles, en moneda de curso legal, y conforme al sistema general de pesos y medidas aplicables al país, sin perjuicio de que el proveedor o anunciante pueda incluir, adicionalmente, esos mismos datos en otro idioma, unidad monetaria o medida.

Tratándose de contratos ofrecidos por medios electrónicos o de aquellos en que se acepte una oferta realizada a través de catálogos, avisos o cualquier otra forma de comunicación a distancia, el proveedor deberá informar, de manera inequivoca y fácilmente accesible, los pasos que deben seguirse para celebrarlos, e informará cuando corresponda, si el documento electrónico en que se formalice el contrato será archivado y si este será accesible al consumidor. Indicará, además, su dirección de correo postal o electrónico y los medios técnicos que ponen a disposición del consumidor para identificar y corregir errores en el envio o en sus datos".

En la misma línea de la "información básica comercial" que fuera garantizada por medio de la Ley $\mathrm{N}^{\circ} 19.955$ el año 2004, el año 2012 la LSF

35 Corral, Hernán (2006), "La aplicación jurisprudencial de la buena fe objetiva en el ordenamiento jurídico chileno", en Cuadernos de Análisis Jurídicos, III, Universidad Diego Portales, pp. 184-226.

36 De la Maza (2010 a) p. 94.

37 De la Maza (2010 a) p. 95.

38 Barrientos, Marcelo (2013), "Artículo $3^{\circ}$ B)", en: Protección de los derechos de los consumidores, comentario a la ley de protección de los derechos de los consumidores, Francisca Barrientos coordinadora, Thomson Reuters, Santiago de Chile, p. 101. 
contempló, en el $\mathrm{N}^{\circ} 1$ de su art. $1^{\circ}$ que "son derechos del consumidor de productos o servicios financieros":

“a) Recibir la información del costo total del producto o servicio, lo que comprende conocer las cargas anuales equivalente a que se refiere el artículo $17 \mathrm{G}$, y ser informado por escrito de las razones del rechazo a la contratación del servicio financiero, las que deberán fundarse en condiciones objetivas.

b) Conocer las condiciones objetivas que el proveedor establece previa y públicamente para acceder al crédito y para otras operaciones financieras.

c) La oportuna liberación de las garantias constituidas para asegurar el cumplimiento de sus obligaciones, una vez extinguidas estas.

d) Elegir al tasador de los bienes elegidos en garantía, entre las alternativas que le presente la institución financiera.

e) Conocer la liquidación total del crédito, a su solo requerimiento".

Esta redacción no ha estado exenta de críticas, como la de José Miguel Lecaros, para quien se trataría de una legislación sobreabundante ${ }^{39}$. En mi opinión, en cambio, la LSF cumple con reafirmar y publicitar un enfoque de protección de los consumidores basado en su acceso a la información a través de un conjunto de derechos de enorme importancia para los consumidores financieros. Y más aún, si consideramos que la infracción de estos deberes no es inocua, ya que da pie a indemnizaciones de daños, siempre que el consumidor pueda probar el supuesto de hecho del deber cuya infracción reclama.

\section{1) LA RESPONSABILIDAD CIVIL POR "INDUCIR A ERROR"}

Entre los derechos y deberes del consumidor que contiene la LPC se destaca el deber del proveedor de informar al consumidor las condiciones del acto de consumo (art. 3). La citada reforma del año 2004 (Ley $\left.\mathrm{N}^{\circ} 19.955\right)$, a propósito de la "información básica comercial” introdujo el deber de que esta información fuese puesta "a disposición de los consumidores, en sus productos o en lugares de venta o de prestación de servicios" ${ }^{40}$. ¿Qué sucede si los proveedores obligados a informar no cumpliesen con alguno de estos deberes en el marco de un acto de consumo de un producto o servicio financiero? La literatura chilena ha distinguido

\footnotetext{
39 Lecaros, José Miguel (2011), “Algunas observaciones al proyecto de ley 'Sernac Financiero ", en Diario Constitucional.

40 SAndoval, Ricardo (2004), Las reformas introducidas por la ley $N^{\circ} 19.955$ de 14 de julio de 2004 a la ley $N^{\circ}$ 19.496, sobre protección de los derechos de los consumidores, Editorial LexisNexis, Santiago de Chile, p. 14.
} 
dos variantes de la responsabilidad en el contexto del consumo ${ }^{41}$ : una "responsabilidad por incumplimiento a la garantía legal" y una "responsabilidad civil derivada del hecho ilícito infraccional". En este sentido, el profesor Hernán Corral señala que:

"Un hecho que es sancionable administrativamente (con multa, por ejemplo) si produce dańo a otro (y el daño es consecuencia directa de la conducta sancionada), da lugar a ambas responsabilidades: contravencional (para los efectos de cumplir la sanción legal impuesta) y civil (para reparar el daño producido). Si bien emanadas del mismo hecho, la responsabilidad preparatoria (civil) y la sancionatoria (penal o contravencional) se rigen por normas y principios diferentes. Por razones de economía procesal, se suele admitir que un mismo proceso judicial sirva para dilucidar la existencia de ambos tipos de responsabilidad" 42 .

Ahora bien, no hay dudas en cuanto a que los consumidores en Chile tienen "el derecho a la reparación e indemnización adecuada y oportuna de todos los daños materiales y morales en caso de incumplimiento de cualquiera de las obligaciones contraídas por el proveedor" (art. 3 e LPC). Como ejemplos del reconocimiento de la "responsabilidad civil derivada del hecho ilícito infraccional" se pueden citar los casos Fierro con Clínica Alemana Osorno ${ }^{43}$, SERNAC con Falabella ${ }^{44}$, SERNAC con CIA. Telecomunicaciones de Chile S.A. ${ }^{45}$, Ramirez con Hotelera los Nogales ${ }^{46}$, SERNAC

41 Ver, Barrientos, Francisca (2011), "Derecho del consumo", en Revista Chilena de Derecho Privado, $\mathrm{N}^{\circ}$ 17, Universidad Diego Portales, pp. 265-267; Barrientos, Francisca (2010), "La responsabilidad civil del fabricante bajo el artículo 23 de la ley de protección de los derechos de los consumidores y su relación con la responsabilidad civil del vendedor", en Revista Chilena de Derecho Privado, N 14, Universidad Diego Portales, pp. 109-158; GueRRERo, José (2008), "La distinción entre contravención infraccional e incumplimiento contractual o contravención civil en materia de protección de derechos del consumidor", en Colección de estudios de derecho civil en homenaje a la profesora Inés Pardo de Carvallo, Alejandro Guzmán Brito compilador, Ediciones Universidad de Valparaíso, Valparaíso, pp. 433-454; IвÁÑez, Paula y Opazo, Marcela (2004), Responsabilidad infraccional de los proveedores en la ley 19.496 y su vinculación con el ámbito penal, Memoria de Grado, Universidad de Chile (Germán Vidal y Mario Rolando profesores guía), 62 pp.

42 Corral, Hernán (2003), Lecciones de responsabilidad civil extracontractual, Editorial Jurídica de Chile, Santiago, p. 23. Véase, además, Corral, Hernán (2011), Responsabilidad por productos defectuosos, análisis y propuestas para el derecho civil y de consumo en Chile, AbeledoPerrot, Santiago de Chile, p. 111.

43 Juzgado de Policía Local de Osorno, 24 septiembre 2008, Rol N 4099-06 (redacción del Juez Ignacio Sierpe).

44 Juzgado de Policía Local, 16 marzo 2008, Rol N 5487-1-2007 (redacción de la Jueza Carlota Martínez).

45 Primer Juzgado de Policía Local de Providencia, 29 agosto 2006, Rol N 20035-12-05 (redacción de la Jueza Ana Palma).

46 Segundo Juzgado de Policía Local de Providencia, 5 abril 2007, Rol Nº 11331-f (redacción de la Jueza Estela Martínez). 
con COPEC S.A. ${ }^{47}$, Imaña con Empresa de Transporte Tur Bus ${ }^{48}$, Muñoz con DUOC UC ${ }^{49}$ y SERNAC con Televisión Nacional de Chile ${ }^{50}$.

El desafío de la LSF, entonces, pasa porque los jueces fundamenten su decisión en cada uno de estos puntos: al decidir que concurre el supuesto de hecho del deber y establecer su incumplimiento. Ello es realmente arduo si consideramos que el deber de cuidado en el mercado de productos financieros y de seguros ha sido construido a la luz de un vicio de nulidad: "inducir a error" al consumidor, el que a diferencia del art. 28 LPC exige que "dicha inducción haya sido determinante" 51 . En efecto, el art. 17 L) LSF dispone que:

"Los proveedores de servicios y productos financieros que entreguen la información que exige esta ley de manera que induzca a error al consumidor o mediante publicidad engañosa, sin la cual no se hubiere contratado el servicio o producto, serán sancionados con las multas previstas en el artículo 24 en sus respectivos casos, sin perjuicio de las indemnizaciones que pueda determinar el juez competente de acuerdo a la presente ley".

Esta conexión entre el deber de cuidado y el vicio del consentimiento se hace explícita al revisar las medidas que contempla la LSF para hacer frente a los casos en que los proveedores no informan al consumidor o le informan de manera incompleta y tardía, o bien, de forma excesiva (sea que ello califique o no como "publicidad engañosa"), con infracción a los derechos del consumidor y a los deberes de los proveedores.

\section{2) LAS SANCIONES DE LA LEY $\mathrm{N}^{\circ}$ 20.555: NULIDAD, MULTAS $\mathrm{Y}$ RESPONSABILIDAD CIVIL}

La regulación del mercado de productos financieros que contempla la LSF ha introducido como sanciones a la nulidad de la cláusula (o del acto), la multa y la responsabilidad por los perjuicios ocasiones ${ }^{52}$. En lo que se refiere a la nulidad el art. 17 E) LSF dispone lo siguiente:

\footnotetext{
47 Tercer Juzgado de Policía Local de Santiago, 22 julio 2008 (redacción del Juez Héctor Jerez).

48 Tercer Juzgado de Policía Local Arica, 28 abril 2008, Rol Nº 159/NA (redacción de la Jueza Coralí Aravena).

49 Primer Juzgado de Policía Local de Las Condes, 1 octubre 2007, Rol N 43270-3-2006 (redacción del Juez Luis Sepúlveda).

50 Juzgado de Policía Local de Providencia, 2 mayo 2007, Rol Nº 15105-11-2006 (redacción del Juez Juan Pérez).

51 Fernández, Fernando (2013), “Artículo 17 L”, en: Protección de los derechos de los consumidores, comentario a la ley de protección de los derechos de los consumidores, Francisca Barrientos coordinadora, Thomson Reuters, Santiago de Chile, p. 511.

52 Véase, Lorenzini, Jaime (2012), "SERNAC Financiero: fundamentos y perspectivas", en Revista de Derecho, N², Universidad de Chile, pp. 267-280.
} 
"El consumidor financiero podrá solicitar la nulidad de una o varias cláusulas o estipulaciones que infrinjan el art. 17 B. Esta nulidad podrá declararse por el juez en el caso de que el contrato pueda subsistir con las restantes cláusulas o, en su defecto, el juez podrá ordenar la adecuación de las cláusulas correspondientes, sin perjuicio de la indemnización que pudiere determinar a favor del consumidor.

Esta nulidad solo podrá invocarse por el consumidor afectado, de manera que el proveedor no podrá invocarla para eximirse o retardar el incumplimiento parcial o total de las obligaciones que le imponen los respectivos contratos a favor del consumidor".

En cuanto a las multas, el art. $17 \mathrm{~K}$ ) LSF señala que:

"El incumplimiento por parte de un proveedor de lo dispuesto en los artículos 17 B a $17 \mathrm{~J}$ y de los reglamentos dictados para la ejecución de estas normas, que afecte a uno o más consumidores, será sancionado como una sola infracción, con multas de hasta setecientos cincuenta unidades tributarias mensuales".

Esto va de la mano con lo que señala el art. 24 inciso 2 LPC, con respecto a los casos de "publicidad falsa o engañosa":

"La publicidad falsa o engañosa difundidos por medios de comunicación social, en relación a cualquiera de los elementos indicados en el art. 28, hará incurrir al infractor en una multa de hasta 750 unidades tributarias mensuales. En caso de que incida en las cualidades de productos o servicios que afecten la salud o la seguridad de la población o el medio ambiente, hara incurrir al anunciante infractor en una multa de hasta 1.000 unidades tributarias mensuales".

En tercer lugar, en lo que se refiere a la responsabilidad civil ("derivada de un hecho ilícito infraccional") el aspecto más relevante de la LSF, a mi juicio, es dirimir cuándo el proveedor ha entregado información de un modo que "induzca a error al consumidor" (art. 17 L LSF). Esta regla, como se puede observar, continúa la senda que trazó el art. 28 LPC, según el cual "comete infracción a las disposiciones de esta ley el que, a sabiendas o debiendo saberlo y a través de cualquier tipo de mensaje publicitario induce a error o engaño", pero el art. 17 L LSF debido a su redacción se independiza de estar circunscrito solo a los mensajes publicitarios que inducen a error a los consumidores financieros, ya que la ley entiende que en los mercados financieros y de seguros existen diferentes formas de inducir a error a un consumidor financiero más que por la sola publicidad falsa o engañosa. A efectos de interpretar en qué casos puede hablarse de error (y de qué clase de error se habla) es importante traer a colación el art. $17 \mathrm{~B}$ ) inciso $1^{\circ} \mathrm{LSF}$, por cuanto alude a un "mínimo" de información 
(no agotándose en la exigida por la LSF) que deben aportar los proveedores financieros con el objeto de que el consumidor financiero la reciba con un grado óptimo de "simplicidad y transparencia":

"Los contratos de adhesión de servicios crediticios, de seguros y, en general, de cualquier producto financiero, elaborados por bancos e instituciones financieras o por sociedades de apoyo a su giro, establecimientos comerciales, compañias de seguros, cajas de compensación, cooperativas de ahorro y crédito, y toda persona natural o juridica proveedora de dichos servicios o productos, deberán especificar como minimo, con el objeto de promover su simplicidad y transparencia, lo siguiente: a) Un desglose pormenorizado de todos los cargos, comisiones, costos y tarifas que expliquen el valor efectivo de los servicios prestados, incluso aquellos cargos, comisiones, costos y tarifas asociados que no forman parte directamente del precio o que corresponden a otros productos contratados simultáneamente $y$, en su caso, las exenciones de cobro que correspondan a promociones o incentivos por uso de los servicios y productos financieros".

A modo de ejemplo se puede notar que una aplicación de este art. 17 B) se encuentra en el $17 \mathrm{G}$ ) inciso $1^{\circ} \mathrm{LSF}$ :

"Los proveedores deberán informar la carga anual equivalente en toda publicidad de operaciones de crédito en que se informe una cuota o tasa de interés de referencia y que se realice por cualquier medio masivo o individual. En todo caso, deberán otorgar a la publicidad de la carga anual un tratamiento similar a la de la cuota o tasa de interés de referencia, en cuanto a tipografía de la gráfica, extensión, ubicación, duración, dicción, repeticiones y nivel de audición".

En definitiva, tras la lectura del art. 17 en sus letras E), B) G) y L) LSF resulta evidente el propósito de proteger la libertad de los contratantes de servicios financieros mediante deberes de información que pretenden velar por "la integridad de la voluntad" 53 de quien contrata y por disminuir las asimetrías en los mercados financieros. El propósito no es solo entregar más información, sino que mejor información, en donde la mejoría de la información está directamente vinculada a la comprensión por parte del consumidor. Así esta regulación se podrá interpretar correctamente si el consumidor financiero se entiende como un "consumidor medio" y no como un "consumidor vulnerable". Así, por ejemplo, en el caso SERNAC con Empresa Comercial Hites S.A., se consideró que un anuncio publicitario inducía a error con el eslogan " 2 x 1 Hites, no se pierda los últimos días 2 x 1 Hites, lleve 2 y pague 1 ” y, tras sucesivas

53 Domínguez Águila, Ramón (1977), Teoría general del acto jurídico, Editorial Jurídica de Chile, Santiago, p. 57. 
imágenes, "aproveche las mejores ofertas con las cuotas más bajas del mercado", indicando que el mensaje era engańoso, puesto que incentivaba a los consumidores a adquirir dos productos y pagar solo uno, en circunstancias de que no se trataba de una promoción sino que de una rebaja de precios para parejas de productos previamente establecidos ${ }^{54}$. Si bien no se trata de un caso específico de consumo de productos financieros, el fallo es significativo porque parece abrazar una idea demasiado fuerte de "inducir a error" al consumidor.

Habrá que ver de qué modo nuestros tribunales se hacen cargo de las reglas del consumo financiero antes mencionadas: si con una interpretación amplia como la de SERNAC con Empresa Comercial Hites S.A. o, por el contrario, por medio de una idea más matizada de error. Los derechos y deberes de los consumidores, y especialmente los deberes de información que se establecen en favor del consumidor financiero como un "consumidor medio", al ser transgredidos se pueden traducir en nulidades, multas e indemnizaciones, con un art. $17 \mathrm{~L}$ ) que tendría que actuar como el eje central para la elaboración de una demanda indemnizatoria de perjuicios que procure satisfacer los intereses del consumidor por la infracción de los deberes del proveedor.

\section{CONCLUSIONES}

La historia legislativa del derecho de los consumidores es, en cierto modo, una historia del acceso a más y mejor información. Los años 1997, 2004 y 2012 constituyen tres hitos al respecto. El año 2012, con la entrada en vigencia de la Ley $\mathrm{N}^{\circ} 20.555$, los consumidores cuentan con derecho a ser informados sobre aspectos relevantes de la relación contractual con su proveedor de productos financieros. Esta información va en refuerzo de la confianza que deposita el consumidor en el mercado financiero y en sus principales actores.

La regulación de la Ley $\mathrm{N}^{\circ} 20.555$ se orienta a que el consumidor financiero sea tratado como un "consumidor medio", que requiere de una información "simple" y "transparente" a la hora de tomar decisiones de consumo en un mercado encriptado. En el caso de que el consumidor financiero sea "inducido a error", la Ley $\mathrm{N}^{\circ} 20.555$ contempla un triple sistema sancionatorio, basado en acciones de nulidad, en multas e indemnizaciones de perjuicios por los hechos ilícitos infraccionales del proveedor.

Corte de Apelaciones de Santiago, 11 junio 2004, Rol N 7250-2002 (redacción del Ministro Juan Fuentes). 


\section{BIBLIOGRAFÍA CITADA}

- Ariztía, Tomás, Melero, José Manuel y Montero, María José (2010), "Un nuevo consumidor chileno: De los derechos a las responsabilidades", en Chile 2009. Percepciones y actitudes sociales, Universidad Diego Portales, pp. 103-112.

- Barros, Enrique (2006), Tratado de responsabilidad extracontractual, Editorial Jurídica de Chile, Santiago, 1230 pp.

- Barros, Macarena (2012), "En torno al uso del crédito en la industria del retail de Santiago", en Destapando la caja negra / Sociología de los créditos de consumo en Chile, Instituto de Investigación de Ciencias Sociales (ICSO), pp. 113-136.

- Barrientos, Marcelo (2013), "Artículo $3^{\circ}$ B)", en: Protección de los derechos de los consumidores, comentario a la ley de protección de los derechos de los consumidores, Francisca Barrientos coordinadora, Thomson Reuters, Santiago de Chile, pp. 94-103.

- Barrientos, Marcelo (2008), Daños y deberes en las tratativas preliminares de un contrato, Editorial LegalPublishing, Santiago, 142 pp.

- Barrientos, Francisca (2011), "Derecho del consumo", en Revista Chilena de Derecho Privado, $\mathrm{N}^{\circ} 17$, Universidad Diego Portales, pp. 265-267.

- Barrientos, Francisca (2010), "La responsabilidad civil del fabricante bajo el artículo 23 de la ley de protección de los derechos de los consumidores y su relación con la responsabilidad civil del vendedor", en Revista Chilena de Derecho Privado, ${ }^{\circ} 14$, Universidad Diego Portales, pp. 109-158.

- Boletín Crédito Hipotecario (Banca, cooperativa de ahorro y crédito, Agentes administradores y Caja de Compensación), disponible en: www.sernacfinanciero.cl, noviembre 2012, 23 pp.

- Boletín N 01/2013 Tarjetas de Crédito: Avances en efectivo y compra en cuotas con tarjeta de crédito", disponible en www. sernacfinanciero.cl, febrero 2013.

- Celedón, Rosario y Silberman, Patricia (2010), Responsabilidad precontractual por ruptura de negociaciones contractuales, Editorial Jurídica de Chile, Santiago, 162 pp.

- Corral, Hernán (2011), Responsabilidad por productos defectuosos, análisis y propuestas para el derecho civil y de consumo en Chile, AbeledoPerrot, Santiago de Chile, 350 pp.

- Corral, Hernán (2005), "La aplicación jurisprudencial de la buena fe objetiva en el ordenamiento civil chileno", en Cuadernos de Análisis Jurídico, III, Ediciones Universidad Diego Portales, pp. 187226.

- Corral, Hernán (2003), Lecciones de responsabilidad civil extracontractual, Editorial Jurídica de Chile, 424 pp. 
- De la Maza, Íñigo (2010), “Tipicidad y atipicidad de los deberes precontractuales de información", en Revista de Derecho, XXXIV, Pontificia Universidad Católica de Valparaíso, pp. 75-99.

- De la Maza, Íńigo (2010), "El suministro de información como técnica de protección de los consumidores: Los deberes precontractuales de información", en Revista de Derecho Universidad Católica del Norte, año 17, $\mathrm{N}^{\circ}$ 2, pp. 21-52.

- De la Maza, Íñigo (2005), "El silencio de los inocentes: Hacia una categorización del deber de informar en sede precontractual", en Estudios de Derecho Civil, LexisNexis, pp. 128-177.

- Domínguez Águila, Ramón (1977), Teoría general del acto jurídico, Editorial Jurídica de Chile, 284 pp.

- Fernández, Fernando (2013), "Artículo 17 L", en: Protección de los derechos de los consumidores, comentario a la ley de protección de los derechos de los consumidores, Francisca Barrientos coordinadora, Thomson Reuters, Santiago de Chile, pp. 504-512.

- Gómez Pomar, Fernando (2003), "La relación entre normativa sobre protección de consumidores y normativa sobre defensa de la competencia. Una visión desde el análisis económico del derecho", en Revista InDret.

- Ghersi, Carlos y Weingarten, Celia (2000), Contratos bancarios, aplicación de la ley del consumidor, Editorial Jurídica Nova Tesis, Rosario, 184 pp.

- Guerrero, José (2008), “La distinción entre contravención infraccional e incumplimiento contractual o contravención civil en materia de protección de derechos del consumidor", en Colección de estudios de derecho civil en homenaje a la profesora Inés Pardo de Carvallo, Alejandro Guzmán Brito compilador, Ediciones Universidad de Valparaíso, Valparaíso, pp. 433-454.

- IвáÑez, Paula y Opazo, Marcela (2004), Responsabilidad infraccional de los proveedores en la ley 19.496 y su vinculación con el ámbito penal, Memoria de Grado, Universidad de Chile (Germán Vidal y Mario Rolando profesores guía), $62 \mathrm{pp}$.

- Isler, Érica (2011), "La relatividad de los derechos subjetivos de los consumidores", en Revista de Derecho de Valdivia, vol. XXIV. N ${ }^{\circ} 2$, pp. 65-89.

- Isler, Érica (2010) "Aproximaciones a la publicidad engañosa, desde la perspectiva de la competencia desleal y la protección", en Ars Boni et Aequi, $\mathrm{N}^{\circ}$ 6, pp. 125-145.

- Lecaros, José Miguel (2011), "Algunas observaciones al proyecto de ley 'Sernac Financiero'”, en Diario Constitucional, diciembre 2011.

- Lorenzini, Jaime (2012), "SERNAC Financiero: fundamentos y perspectivas", en Revista de Derecho, N ${ }^{\circ}$ 2, Universidad de Chile, pp. 267-280. 
- Ministerio de Economía, Fomento y Turismo, División de Estudios: "Efectos de la nueva regulación en los seguros de créditos hipotecarios. Análisis en base a la disminución de costos debido a la Ley N ${ }^{\circ} 20.552 "$ ", septiembre 2012.

- Morales, Thamara (2010), Mejores prácticas de educación financiera aplicadas a productos de crédito en el mercado chileno, Facultad de Ciencias Físicas y Matemáticas Departamento de Ingeniería Industrial, Universidad de Chile (William Baeza profesor guía), 211 pp.

- Narotzky, Susana (2007), "El lado oculto del consumo", en Cuadernos de antropología social, $\mathrm{N}^{\circ} 26$, pp. 21-39.

- Ossandón, José (2012), Destapando la caja negral Sociología de los créditos de consumo en Chile, Instituto de Investigación de Ciencias Sociales, $136 \mathrm{pp}$.

- Rose, Carol (2010), "Confianza y traición", en El derecho de propiedad como clave interdisciplinaria, Primera Edición, Lucas Grosmman editor, Universidad de Palermo, Buenos Aires, pp. 133157.

- Salgado, Catalina (2011), El deber precontractual de información. Contornos desde la perspectiva del sistema del "Ius Romanum» por interacción vertical a partir de la "Ignorantia Factie et Iuris» y la compraventa en el derecho romano, Universidad Degli Studi di Roma "Tor Vergata", 214 pp.

- Sandoval, Ricardo (2004), Las reformas introducidas por la ley $N^{\circ}$ 19.955 de 14 de julio de 2004 a la ley $N^{\circ} 19.496$, sobre protección de los derechos de los consumidores, Editorial LexisNexis, Santiago de Chile, 207 pp.

- San Martín, Lilian (2013), "Responsabilidad precontractual por ruptura injustificada de negociaciones", en Revista Chilena de Derecho, Vol. $40 \mathrm{~N}^{\circ}$ 1, Pontificia Universidad Católica de Chile, pp. 317-324.

- San Martín, Lilian (2013), "Artículo 3 inciso 20", en Protección de los derechos de los consumidores, comentario a la ley de protección de los derechos de los consumidores, Francisca Barrientos coordinadora, Thomson Reuters, Santiago de Chile, pp. 140-150.

- Tapia, Mauricio y Valdivia, José Miguel (2002), Contrato por adhesión Ley $N^{\circ}$ 19496, Editorial Jurídica de Chile, Santiago, 199 pp.

- Venire contra Factum propium. Escritos sobre la fundamentación, alcance y límites de la doctrina de los actos propios (2010), en Cuadernos de Extensión Jurídica, $\mathrm{N}^{\circ} 18$, Universidad de los Andes, Hernán Corral Talciani editor, 151 pp.

- Von Ihering, Rudolf (1872), La lucha por el derecho, traducción de Adolfo González Posada, Editorial Heliasta S.R.L, 128 pp. 
- Weingarten, Celia (2007) Derecho del consumidor, Editorial Universitaria, Buenos Aires, 408 pp.

\section{JURISPRUDENCIA CITADA}

- Juzgado de Policía Local, 14 noviembre 2005, Rol N 65311 2005, LegalPublishing: CL/JUR/7534/2005.

- Juzgado de Policía Local Providencia, 29 agosto 2006, Rol Nº 20035-12-05 (redacción de la Jueza Ana María Palma).

- Segundo Juzgado de Policía Local de Providencia, 5 abril 2007, Rol N 11331-f (redacción de la Jueza Estela Martínez).

- Primer Juzgado de Policía Local de Providencia, 2 mayo 2007, Rol N 15105-11-2006 (redacción del Juez Juan Pérez).

- Juzgado de Policía Local de Lo Barnechea, 12 junio 2007, Rol No 90268-2007, LegalPublishing: CL/JUR/6387/2007.

- Primer Juzgado de Policía Local de Las Condes, 1 octubre 2007, Rol N 43270-3-2006 (redacción del Juez Luis Sepúlveda).

- Tercer Juzgado de Policía Local de Arica, 28 abril 2008, Rol N ${ }^{\circ}$ 159/NA (redacción de la Jueza Coralí Aravena).

- Juzgado de Policía Local, 16 marzo 2008, Rol N 5487-1-2007 (redacción de la Jueza Carlota Martínez).

- Tercer Juzgado de Policía Local de Santiago, 22 julio 2008 (redacción del Juez Héctor Jerez).

- Juzgado de Policía Local Osorno, 24 septiembre 2008, Rol N ${ }^{\circ}$ 4099-06 (redacción del Juez Ignacio Sierpe).

- Juzgado de Policía Local de Las Condes, 12 enero 2009, Rol N 47174-2008, LegalPublishing: CL/JUR/9980/2009.

- Corte de Apelaciones de Santiago, 11 de junio 2004, Rol N7250-2002 (redacción del Ministro Juan Fuentes).

- Corte Suprema, 11 mayo 2011, Rol N 8931-2011, LegalPublishing: CL/JUR/888/2012.

- Corte Suprema, 11 mayo 2012, Rol $N^{\circ}$ 8935-2011, LegalPublishing: CL/JUR/892/2012. 